\title{
EMERGING TOOLS FOR EVALUATING SAFETY MANAGEMENT SYSTEMS EFFECTIVENESS
}

\author{
T. BRADY \& A. STOLZER \\ Daytona Beach Campus, Embry-Riddle Aeronautical University, FL, USA
}

\begin{abstract}
Safety Management Systems (SMS) have become prevalent in a host of industries, including aviation, for managing safety, but little research has been performed to-date on measuring the effectiveness of SMS. This research examined the independent application of two related concepts to assess effectiveness: IO/SMS, an Input-Output economics concept applied to SMS, and Data Envelopment Analysis (DEA). Input-Output (IO) is a method for systematically determining the inter-relationships among elements in a system. To determine if IO could be applied to SMS, it was necessary to calculate the relative importance to the system of the four components of SMS. Five SMS experts participated and, through a series of exercises, determined values for the 24 discrete SMS parts. Using IO matrix math, these values were then calculated for a $24 \times 24$ matrix. The results produced a matrix that could be used to predict the impact on the system by changing either a total input value such as an aggregate score on a survey, or by changing a single value. DEA is a multi-factor, mathematical programming technique that is used to determine the boundary of an efficient frontier. Using inputs and outputs, a ratio is calculated, which measures the relative efficiency, or effectiveness, of each decision making unit (DMU). In this research, inputs and outputs were determined for each of the four components of SMS via surveys conducted by subject matter experts. DEA models were developed and tested, and efficiency scores were developed for each DMU. DEA modeling also revealed the specific areas that could be addressed to improve efficiency scores. IO/SMS and DEA appear to be powerful tools to measure SMS effectiveness. A next step in the research may be to examine techniques that combine the benefits of both methods.

Keywords: data envelopment analysis, emerging tools, input-output analysis, safety management systems.
\end{abstract}

\section{INTRODUCTION}

Two operations research and economics methods - Input-Output (IO) and Data Envelopment Analysis (DEA) - were examined in independent but parallel research projects for their usefulness in evaluating Safety Management Systems (SMS) effectiveness. Each of these methods as it applies to SMS is briefly described below, including recommendations for further study.

\section{REVIEW OF LITERATURE}

In 2006, following the lead of numerous industries that have implemented SMS, the International Civil Aviation Organization (ICAO) published a standard requiring member states to establish SMS. Since that time, SMS has become the worldwide standard for managing aviation safety. The European Aviation Safety Agency, which governs air transportation in Greece, implemented SMS rules for air operators in 2011, and in January, 2015, the U.S. 
Federal Aviation Administration (FAA) released a congressionally mandated final rule on SMS for Part 121 air carriers [1].

According to the ICAO, SMS is a 'systematic approach to managing safety, including the necessary organizational structures, accountabilities, policies and procedures' [2]. SMS is a data-driven system to manage risk and is considered a fundamental business process. These characteristics can be found in the SMS Framework developed by the ICAO, which includes 4 components, 12 elements, and 17 processes [3].

The goal of SMS is to ensure safe operation of aircrafts through effective management of risk; that is, the identification of hazards, collection and analysis of data, and continuous assessment of risk [ICAO]. SMS is both a philosophy and a methodology [1], and requires top leadership commitment and a strong safety culture. That safety culture is a product of and is vital to a safety-oriented management system, and is developed and continuously improved through the efforts of all persons throughout every level of the organization.

In spite of the worldwide commitment toward implementing SMS in the aviation industry, an effort that represents significant financial and human capital expenditures, there is little work being done to develop a model for determining the effectiveness of an SMS. Most of the tools developed to-date are merely audit tools that aid in determining the degree to which SMS has been implemented, which is not the same as determining whether SMS is effective in helping an organization achieve its safety goals through risk management.

Through a comprehensive literature search and evaluation of tools used in a variety of applications and domains, it was determined to consider mixed methods, mathematically based tools that could be assessed for validity and reliability. This led to the exploration of IO and DEA for determining SMS effectiveness.

\section{INPUT-OUTPUT ANALYSIS}

"Input-Output analysis is a method of systematically quantifying the mutual interrelationships among the various sectors of complex economic system" [4]. "... each component of any entity contributes to the activities of the other components, and is assisted by them in the completion of its own functions" [5]. This is illustrated by referring to the matrix shown in Table 1. Row two indicates the contributions of agriculture, manufacturing, and households to produce 100 bushels of wheat. Agriculture by itself cannot produce wheat; rather, the agriculture sector is dependent on both of the other two sectors to produce the output [4]. The relationships between each of these components can be determined and the resulting matrix can be used to show how a change in one component can affect all of the other components in the system.

\subsection{Review of the IO applications literature}

Is IO a model that applies only to the discipline of economics? This question led to a literature review to determine the utility of IO to disciplines outside of economics. As the review will show, IO has been broadly applied across a wide spectrum.

As Leurent and Windisch [6] point out, IO has been used in accountancy, environmental economics, carbon footprinting, land appropriation, and on the effects of catastrophic events such as 'the Katrina landfall in Louisiana'. The military has found uses for IO. The Navy used an application of IO to determine the system-wide impact of repositioning ships Sorensen and Willis [7]. The Army has used IO to examine personnel movements and the effects of various military policy decisions [8]. The guiding principle the Army used was 'the principles of input-output analysis can also be applied to the study of an organization'. IO is also used 
Table 1: Leontief's classic input-output matrix.

\begin{tabular}{lllll}
\hline Into & Sector 1 & Sector 2 & Sector 3 & \\
\hline From & Agriculture & Manufacturing & Households & Total Output \\
\hline Agriculture & 25 & 20 & 55 & 100 bushels of wheat \\
Manufacturing & 14 & 6 & 30 & 50 yards of cloth \\
Households & 80 & 180 & 40 & 300 man-years of labor \\
\hline
\end{tabular}

to conduct life-cycle analysis of some equipments such as refrigerators, computers, office equipment, and other electronic goods [9]. It is clear that "Leontief's model has been extended and applied to myriad problems" [10]. As stated by San Cristobal and Biezma [11] "input-output modeling is a useful tool in policy analysis ..." Indeed, in this study, the IO model was used to detect inter-industry linkages within the mining industry in Europe. Lee and Mokhtarian [12] applied IO techniques to analyze the relationship between transportation and communications as industrial inputs. There have been attempts to use IO in health care analysis. In one particular study in Poland, the researchers concluded that an insufficient flow of data was available to make the analysis useable [13]. Interestingly, this article also addressed the use of DEA and described it as 'a non-parametric method of acquiring efficiency'. Regarding the idea of applying IO to a system other than an economic one, as in the case of the hospital management community, Correa et al. [8] explain how components within a system contribute to one another: 'If these interdependencies are not explicitly considered, the system as a whole is not able to function as effectively as possible [5]'.

\subsection{Research question}

Given the success of the IO model in economics as well as in other disciplines, it seemed likely that the IO concepts could be applied to almost anything claiming to be a system. Would it work in an SMS program? It was this question that led a team of researchers to begin exploring whether or not IO could be used to analyze and evaluate SMS. As Correa et al. [8] noted, 'a great deal of flexibility can be used in the specification of the components of any system to be analyzed with input-output methods'.

\subsection{Methods}

A team of five SMS experts and a facilitator met to consider the research question. The problem was broken down into several parts [14]: 1) To determine the relative importance of each of the four major components of SMS, (a) Safety Policy and Objectives (SPO), (b) Safety Risk Management (SRM), (c) Safety Assurance (SA) and (d) Safety Promotion (SP), to the whole; 2) To determine the interdependencies between each SMS component and the others. 3) To determine the distribution of values within each SMS component (termed vertical distribution). 4) To insert the values into a $24 \times 24$ matrix. 5) To calculate the $24 \times 24$ IO matrix for SMS.

\subsection{Applying IO to SMS}

It was first necessary to determine the relative importance of the four major components of SMS, (1) SPO, (2) SRM, (3) SA and (4) SP, to the whole. 


\subsubsection{Relative importance}

The team leader asked five volunteer members, each of whom was considered an expert in SMS, to participate in the experiment in which marbles were used as a metaphor for relative importance of each of the four major components of the SMS. The participants were instructed to place up to 100 in each of the component 'baskets' based on their judgment of the relative worth of each of the components to the whole system. This exercise produced the following results, which represent the relative importance of each of the SMS components to the overall system (Table 2):

\subsubsection{Interdependencies}

The next objective was to determine the interdependencies between each component and the others. As Tiganescu et al. observed [15], it is necessary in an IO analysis, even one dealing with the purpose of this type, to study the interdependence of the components as well as their connections with other parts. Clearly, determining the interdependencies is a cornerstone concept of IO. This exercise was repeated by each participant for each component and the following results were obtained (Table 3):

\subsubsection{Vertical distribution}

With the interdependency data established, it was now necessary to create the distribution of values relative to each component because most components have elements and processes. Each of these elements or processes has a discrete relationship with its component. To fully describe the component, it became necessary to determine what numerical role each of the elements played. To do this, a series of vertical distribution exercises were engaged.

The next step was to create a matrix that captured all of the relational data. Since there were 24 discrete categories ( 7 elements and 17 processes), a $24 \times 24$ matrix was determined and was used to calculate the IO matrix.

Table 2: A determination of the averages for each component. The number 0.292, for example, means that $29.2 \%$ of the total of $100 \%$ is accounted for by component 1 , Safety Policy and Objectives (SPO).

\begin{tabular}{lllllll}
\hline Percentages by participants & 1 & 2 & 3 & 4 & 5 & Average $^{1}$ \\
\hline Safety Policy and Objectives (SPO) & 0.340 & 0.229 & 0.279 & 0.294 & 0.320 & 0.292 \\
Safety Risk Management (SRM) & 0.260 & 0.243 & 0.294 & 0.235 & 0.160 & 0.238 \\
Safety Assurance (SA) & 0.220 & 0.271 & 0.250 & 0.221 & 0.120 & 0.216 \\
Safety Promotion (SP) & 0.180 & 0.257 & 0.176 & 0.250 & 0.400 & 0.253 \\
Total & 1.000 & 1.000 & 1.000 & 1.000 & 1.000 & 1.000 \\
\hline
\end{tabular}

${ }^{1}$ Average of all inputs

Table 3: The interdependency between each component and the others.

\begin{tabular}{llllll}
\hline Interdependencies by component & SPO & SRM & SA & SP & Total \\
\hline SPO & 100 & 85 & 45 & 62 & 292 \\
SRM & 46 & 115 & 51 & 26 & 238 \\
SA & 48 & 56 & 84 & 28 & 216 \\
SP & 53 & 58 & 43 & 99 & 253 \\
\hline
\end{tabular}




\subsubsection{The resulting IO-SMS matrix}

The SMS matrix that resulted from this experiment may be a powerful management tool. The sum of $\mathrm{x}$, for example, can be data from any source. In the case of the example provided, the data source is a hypothetical SMS questionnaire that had the score of 400 as a goal; that number is reflected at the bottom of the 'Goal' column. The maximum attainable value is 600 (10 points each for 60 questions). Once the hypothetical survey was administered, the composite score (the total of the response values) was 330 (sum of $\mathrm{x}$ ). Note the distribution of values in the 'Actual' column. One can compare the desired values in the 'Goal' column to the values in the 'Actual' column to see where the greater deficiencies lie (Table 4). Taken one step further, since the maximum score available is 600 and each of the 24 discrete elements has a value related to 600 , one can not only compare the Actual values obtained to those of the Goal but also to the Maximum available.

\subsection{What if}

Another important artifact of the SMS IO matrix is the capability of the matrix to determine the outcome if a point value is changed. Given that SMS practitioners are often resource limited, the matrix provides a method for determining what investment might produce the biggest rewards by assessing how one changed component affects the overall SMS.

\subsection{Weakness}

The matrix is very sensitive to the original input data that define the inter-relationships between the components. If these relationships are not correct, then the entire matrix is likely to be incorrect. As an example, note in Table 2 that the average of the averages for the five members for SPO is 0.292 . However, a close examination shows a fairly wide variability in the inputs from the various members, ranging from 0.229 to 0.340 . It is worse in SP, ranging from 0.176 to 0.400 . With such a wide variability, the accuracy of the eventual matrix is questionable. For the IO-SMS to become a useful tool, the variability between the subject matter experts should be reduced to an acceptable range.

\section{DATA ENVELOPMENT ANALYSIS}

DEA is a linear program method that determines the boundaries of an efficient frontier. Developed in 1978 by Charnes, Cooper, and Rhodes [16], the multi-factor analysis technique calculates the ratio between inputs and outputs to determine the efficiency (or effectiveness) of decision making units (DMUs, or organizations). The performance of a DMU is calculated by comparing its efficiency with the best observed performance in the data set, which is accepted as the efficient frontier. The mathematical model for DEA is given as:

$$
\max \sum_{i=1}^{n} \boldsymbol{u}_{i} \boldsymbol{y}_{i p}
$$

s.t.

$$
\sum_{j=1}^{m} w_{j} x_{j p}=1
$$


Table 4: Shows the relationship of each of the 24 discrete values (shown by an asterisk). The Goal for the survey was 400 , but the Actual achievement was 330 compared to a Maximum attainable of 600 .

\begin{tabular}{|c|c|c|c|c|c|}
\hline Component & Element & Process & Max & Goal & Actual \\
\hline \multirow[t]{5}{*}{$1-\mathrm{SPO}$} & 1.1 Safety Policy* & & 52.8 & 35.2 & 29.0 \\
\hline & 1.2 Management* & & 48.2 & 32.1 & 26.5 \\
\hline & 1.3 Key Safety People* & & 34.8 & 23.2 & 19.1 \\
\hline & 1.4 Emergency Prep* & & 15.2 & 10.1 & 8.3 \\
\hline & 1.5 Documentation* & & 20.7 & 13.8 & 11.4 \\
\hline \multirow[t]{6}{*}{$2-\mathrm{SRM}$} & 2.1 System Analysis \& & 2.1.1 System & 24.9 & 16.6 & 13.7 \\
\hline & Hazard Identification & Description* & & & \\
\hline & & 2.1.2 Identify Hazards* & 41.0 & 27.4 & 22.6 \\
\hline & 2.2 Risk Assessment \& & 2.2.1 Analyze Risk* & 25.5 & 17.0 & 14.0 \\
\hline & Control & 2.2.2 Assess Risk* & 29.2 & 19.5 & 16.1 \\
\hline & & 2.2.3 Mitigate Risk* & 37.9 & 25.3 & 20.9 \\
\hline \multirow[t]{11}{*}{$3-\mathrm{SA}$} & 3.1 Safety Performance & 3.1.1 Monitoring* & 9.6 & 6.4 & 5.3 \\
\hline & Monitoring and & 3.1.2 Internal Audits* & 8.3 & 5.5 & 4.6 \\
\hline & Measurement & $\begin{array}{l}\text { 3.1.3 Internal } \\
\text { Evaluation* }\end{array}$ & 7.1 & 4.7 & 3.9 \\
\hline & & 3.1.4 External Audits* & 13.3 & 8.9 & 7.3 \\
\hline & & 3.1.5 Investigation* & 14.8 & 9.8 & 8.1 \\
\hline & & $\begin{array}{l}\text { 3.1.6 Employee } \\
\text { Reporting* }\end{array}$ & 16.9 & 11.3 & 9.3 \\
\hline & & 3.1.7 Analysis of Data* & 12.7 & 8.5 & 7.0 \\
\hline & & $\begin{array}{l}\text { 3.1.8 System } \\
\text { Assessment* }\end{array}$ & 7.6 & 5.0 & 4.2 \\
\hline & $\begin{array}{l}\text { 3.2 Management of } \\
\text { Change* }\end{array}$ & & 17.5 & 11.7 & 9.6 \\
\hline & $\begin{array}{l}3.3 \text { Continuous } \\
\text { Improvement }\end{array}$ & $\begin{array}{l}\text { 3.3.1 Preventive or } \\
\text { Corrective Action* }\end{array}$ & 15.1 & 10.1 & 8.3 \\
\hline & & 3.3.2 Mgmt Review* & 10.3 & 6.9 & 5.7 \\
\hline \multirow[t]{4}{*}{$4-\mathrm{SP}$} & $\begin{array}{l}4.1 \text { Competencies and } \\
\text { Training }\end{array}$ & $\begin{array}{l}\text { 4.1.1 Personnel } \\
\text { Competence* }\end{array}$ & 34.7 & 23.2 & 19.1 \\
\hline & & 4.1.2 Training* & 38.6 & 25.7 & 21.2 \\
\hline & $\begin{array}{l}4.2 \text { Communication \& } \\
\text { Awareness* }\end{array}$ & & 63.2 & 42.2 & 34.8 \\
\hline & * Discrete Values & & 600.0 & 400.0 & $\begin{array}{l}330.0 \\
\text { Sum } \\
\text { of } x\end{array}$ \\
\hline
\end{tabular}




$$
\begin{gathered}
\sum_{i=1}^{n} \boldsymbol{u}_{i} \boldsymbol{y}_{i k}-\sum_{j=1}^{m} \boldsymbol{w}_{j} \boldsymbol{x}_{j k} \leq 0 \forall \boldsymbol{k} \\
\boldsymbol{u}_{i}, \boldsymbol{w}_{j} \geq 0 \forall \boldsymbol{i}, \boldsymbol{j}
\end{gathered}
$$

where

$y_{i k}=$ amount of output $i$ produced by DMU $k$

$x_{j k}=$ amount of input $j$ utilized by DMU $k$

$u_{i}=$ weight given to output $i$

$w_{j}=$ weight given to input $j$

\subsection{Methodology}

Structured interviews were conducted with 22 experts on SMS in the aviation industry. The goal of the interviews was to provide increased understanding of SMS implementation, and inform and revise the draft survey tool that was used for collecting data for the DEA model building process. Interviewees were selected purposefully to obtain input from across the aviation industry, including air carriers, airport operators, regulators, fixed-base operators, and others. Most interviewees were U.S.-based, but some were from Europe and Canada.

The purpose of the survey was to determine the inputs and outputs used for the DEA model for each of the four components of SMS; that is, SPO, SRM, SA, and SP (Table 4) [3]. The survey was pre-tested and modified based on results. The final survey was completed by 33 subjects.

The final survey statistics were assessed for normality and outliers. A Confirmatory Factor Analysis (CFA) model was constructed for each of the four SMS components using AMOS Graphic $^{\circledR}$, and model fit was assessed.

The items derived from reliability and validity tests were used as the inputs to the DEA models. Data conversions were applied as appropriate; for example, all input questions were in Likert scales and required no conversion, but output questions reflected actual SMS performance in various areas, some of which varied by organization size and, thus, conversion was performed to ensure that data were comparable across organizations.

\subsection{Results}

DEA models for each SMS component were developed and tested using Frontier Analysis ${ }^{\circledR}$ software. For the SPO component, the model included six inputs (derived from the CFA test) and three outputs (derived from the survey with conversions as necessary) (Fig. 1).

The DEA model was tested and the efficiency scores were calculated for each DMU. Figure 2 depicts the distribution of those scores for each DMU. DMUs, or organizations, are shown in green color when they are deemed efficient (that is, effective) relative to other DMUs. For this component, there are 6 DMUs that are presently efficient, one DMU that is 81 to $99.9 \%$ efficient (shown in yellow), and 10 DMUs that are less than $10 \%$ efficient (red); all of the remaining DMUs are between 11 and $80 \%$ efficient (red).

A strength of the DEA process is that it indicates where improvement is needed to improve the efficiency score. In the case of the SPO component, it can be seen that the SPO_03, overall budget allocated toward system safety, needed the most improvement (shown in large, 


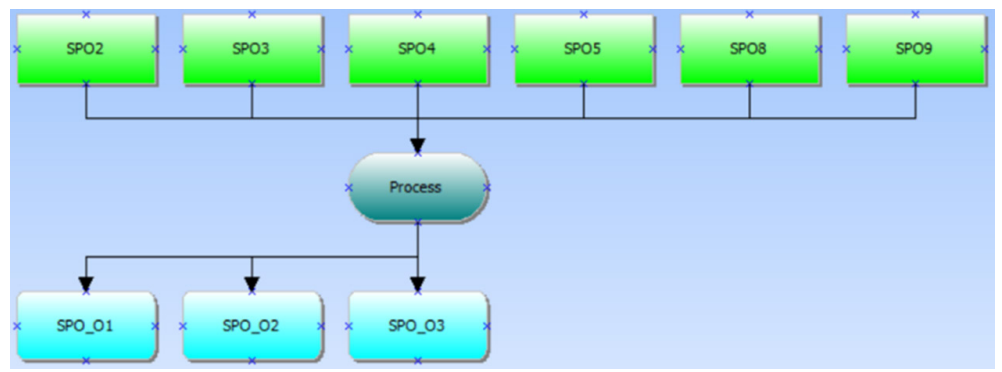

Figure 1: Data Envelopment Analysis model for safety policy and objectives component.

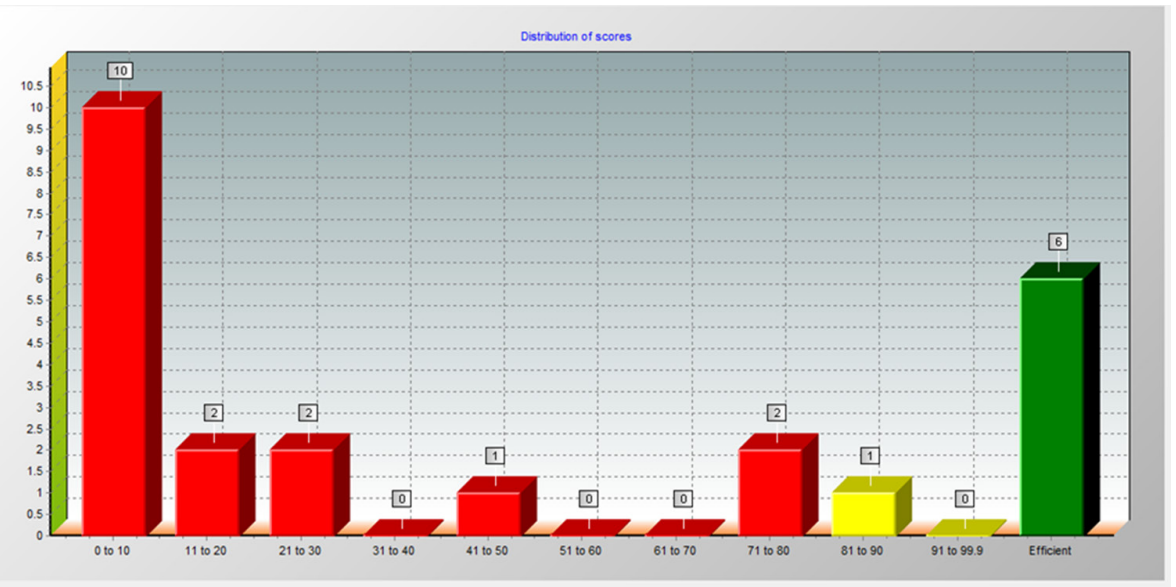

Figure 2: Distribution of scores for the safety policy and objectives component.

$81.67 \%$ green pie slice), followed by SPO_02, number of employees with system safety in their job descriptions (12.26\%), and SPO_01, number of employees with safety in their job titles (5.95\%) (Fig. 3).

Similar analyses were performed on the remaining three components of SMS.

Cronbach's alpha and construct reliability (CR) values for all constructs are shown in Table 5. All values were greater than 0.7 , indicating good CR.

The results of the discriminant validity test are presented in Table 6 . The square root of the Average Variance Extracted (AVE) is shown in bold; the other numbers are the correlation coefficients of the constructs. According to Braunscheidel and Suresh [17], evidence of discriminant validity exists if the square root of AVE of each construct is greater than the correlations in its corresponding row and column. Due to the high correlations among some of the question items in the survey, there was insufficient evidence of discriminant validity. Thus, the final survey was revised to avoid confusion in the questions. Since, in this initial study, DEA models were tested for each component separately, the lack of discriminant validity would not have had a substantial effect on the results. For illustration purposes, the first few questions of the SPO portion of the survey are presented in Fig. 4. 


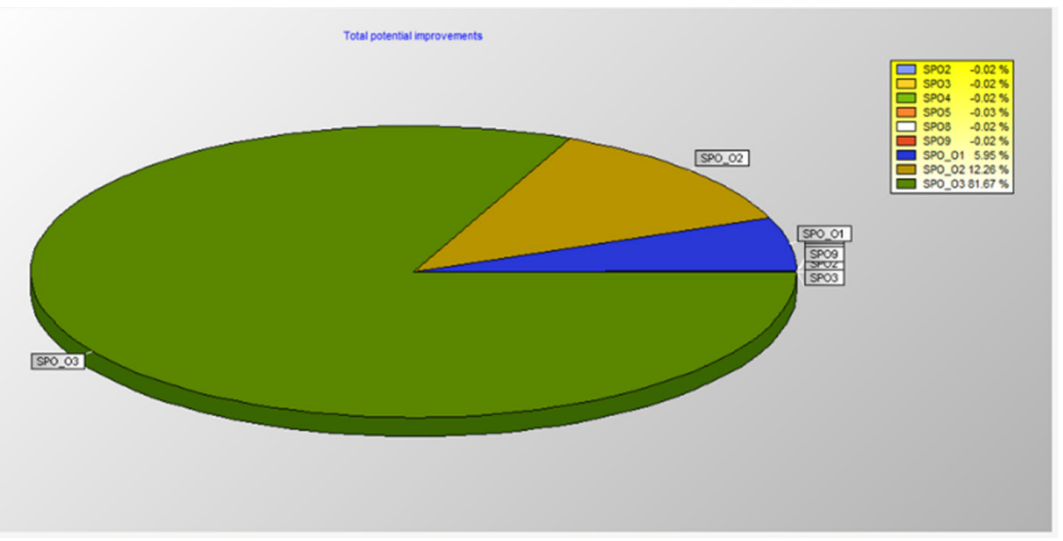

Figure 3: Total potential improvements for safety policy and objectives component.

Table 5: Standardized factor loadings, reliability, and convergent validity.

\begin{tabular}{|c|c|c|c|c|c|}
\hline $\begin{array}{l}\text { Constructs/ } \\
\text { Factors }\end{array}$ & Items & $\begin{array}{l}\text { Standardized } \\
\text { Factor } \\
\text { Loadings }\end{array}$ & $\begin{array}{l}\text { Cronbach's } \\
\text { alpha }\end{array}$ & $\begin{array}{l}\text { Construct } \\
\text { Reliability } \\
\text { (CR) }\end{array}$ & $\begin{array}{l}\text { Average Variance } \\
\text { Extracted (AVE) }\end{array}$ \\
\hline \multirow[t]{6}{*}{ SPO } & SPO2 & 0.803 & \multirow[t]{6}{*}{0.91} & \multirow[t]{6}{*}{0.9} & \multirow[t]{6}{*}{0.72} \\
\hline & SPO3 & 0.93 & & & \\
\hline & SPO4 & 0.903 & & & \\
\hline & SPO5 & 0.787 & & & \\
\hline & SPO8 & 0.809 & & & \\
\hline & SPO9 & 0.865 & & & \\
\hline \multirow[t]{5}{*}{ SRM } & SRM1 & 0.855 & \multirow[t]{5}{*}{0.88} & \multirow[t]{5}{*}{0.88} & \multirow[t]{5}{*}{0.72} \\
\hline & SRM3 & 0.847 & & & \\
\hline & SRM4 & 0.952 & & & \\
\hline & SRM5 & 0.752 & & & \\
\hline & SRM6 & 0.812 & & & \\
\hline \multirow[t]{4}{*}{ SA } & SA2 & 0.947 & \multirow[t]{4}{*}{0.93} & \multirow[t]{4}{*}{0.92} & \multirow[t]{4}{*}{0.83} \\
\hline & SA3 & 0.925 & & & \\
\hline & SA4 & 0.941 & & & \\
\hline & SA8 & 0.821 & & & \\
\hline \multirow[t]{4}{*}{ S P } & SP1 & 0.795 & \multirow[t]{4}{*}{0.92} & \multirow[t]{4}{*}{0.91} & \multirow[t]{4}{*}{0.82} \\
\hline & SP2 & 0.889 & & & \\
\hline & SP3 & 0.97 & & & \\
\hline & SP4 & 0.954 & & & \\
\hline
\end{tabular}

\subsection{DEA implications}

Results from the survey were evaluated using DEA, and relative efficiency scores were calculated for each participating organization. Inefficient organizations were identified and improvements needed to increase their efficiency scores were determined. Reliability and 
Table 6: Discriminant validity assessment.

\begin{tabular}{lllll}
\hline & SPO & SRM & SA & SP \\
\hline SPO & $\mathbf{0 . 8 5}$ & & & \\
SRM & 0.95 & $\mathbf{0 . 8 5}$ & & \\
SA & 0.937 & 0.96 & $\mathbf{0 . 9 1}$ & \\
SP & 0.9 & 0.92 & 0.77 & $\mathbf{0 . 9}$ \\
\hline
\end{tabular}

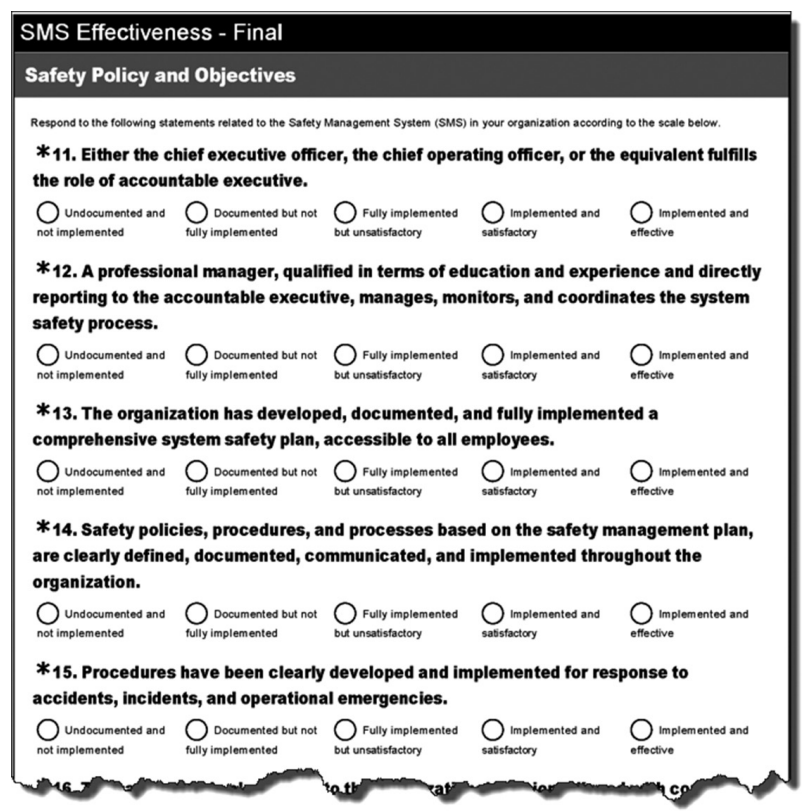

Figure 4: Several survey questions pertaining to safety policy and objectives component.

validity of the survey instrument were established; however, a larger sample size and a more extensive and systematic administration of the instrument needs to be accomplished.

Upon further model refinement, these DEA results can be used to inform a management regarding their position within the group tested, shortcomings in their approach to SMS, and necessary strategies to improve the organization's efficiency. This will provide decision makers a powerful safety management tool, which they do not currently possess.

\section{CONCLUSIONS}

Initial exploration of both IO and DEA to SMS effectiveness provided promising results. More work is needed on larger sample sizes, more subject matter expert participation, and model refinements. Further research is indicated to accomplish this, and to examine where IO and DEA might be employed in a complementary manner to achieve greater benefits.

\section{REFERENCES}

[1] Stolzer, A. \& Goglia, J., Safety Management Systems in Aviation, 2nd ed., Ashgate; Burlington, VT, 2008. 
[2] Safety management manual (SMM), (Doc 9859 AN/474), International Civil Aviation Organization (ICAO), Montréal, Canada, 2013.

[3] Safety Management Systems for Aviation Service Providers, Federal Aviation Administration Advisory Circular/AC 120-92A, 2010, available at http://www.faa.gov/docu mentLibrary/media/

[4] Leontief, W., Input-Output Economic, Oxford University Press: New York, 1986.

[5] Correa, H. \& Parker, B.R., An application of organizational input-output analysis to hospital management. Socio-Economic Planning Sciences, 39, pp. 307-333, 2005. http://dx.doi.org/10.1016/j.seps.2004.09.001

[6] Leurent, F. \& Windisch, E., Benefits and costs of electric vehicles for public finances: an integrated valuation model based on input-output analysis, with application to France. Research in Transportation Economics, 50, pp. 51-62, 2015. http://dx.doi.org/10.1016/j.retrec.2015.06.006

[7] Sorensen, S.W. \& Willis, R.E., Input-output analysis in navy manpower planning. Naval Personnel Research and Development Center TR-77, 26, pp. 1-21, 1977.

[8] Correa, H., Scott W. \& Skovran, J., Military applications of input-output analysis. Defense Analysis, 13(2), pp. 151-167, 1997. http://dx.doi.org/10.1080/07430179708405726

[9] Cobas, E., Hendrickson, C., Lave, L. \& McMichael, F., Economic input/output analysis to aid life cycle assessment of electronics products. IEEE, Symposium on Electronic and the Environment Proceedings, Orlando, FL., pp. 273-278, 1995.

[10] Santos, J.R., May, L. \& El Haimar, A., Risk-based input-output analysis of influenza epidemic consequences on interdependent workforce sectors. Risk Analysis, 33(9), pp. 1620-1635, 2013.

http://dx.doi.org/10.1111/risa.12002

[11] San Cristobal, J.R. \& Biezma, M.V., The mining industry in the European union: analysis of inter-industry linkages using input-output analysis. Resources Policy, 31, pp. 1-6, 2006. http://dx.doi.org/10.1016/j.resourpol.2006.03.004

[12] Lee, T. \& Mokhtarian, P.L., An Input-Output Analysis of the Relationships Between Communications and Travel for Industry, Institute of Transportation Studies, UC Davis, pp. 4-46, 2004.

[13] Jewczak, M. \& Suchecka, J., Application of input analysis in the health care. Comparative Economic Research, 17(4), pp. 87-104, 2014.

http://dx.doi.org/10.2478/cer-2014-0034

[14] Brady, T., Stolzer A., Brickhouse, A., Cortes, A., McCune, D., Raghavan, J. \& Freiwald, D., Marbles: the application of input-output concepts to safety management systems. Journal of Aviation Technology and Engineering, 5(1), pp. 33-43, 2015. http://dx.doi.org/10.7771/2159-6670.1124

[15] Tiganescu, I.E., Mihail, N. \& Sandu, M.T., Input-output analysis and demographic accounting: a tool for educational planning. Theoretical and Applied Economics, 17(7), pp. 37-48, 2010.

[16] Charnes, A., Cooper, W.W. \& Rhodes, E., Measuring the deficiency of decision making units. European Journal of Operational Research, 2(6), pp. 429-444, 1978. http://dx.doi.org/10.1016/0377-2217(78)90138-8

[17] Braunscheidel, M. \& Suresh, N., The organizational antecedents of a firm's supply chain agility for risk mitigation and response. Journal of Operations Management, 27(2), pp. 119-140, 2009.

http://dx.doi.org/10.1016/j.jom.2008.09.006 